\title{
ELEVATION OF THE MAXIMAL SEIZURE THRESHOLD PRODUCED BY CALCIUM HYDROXIDE IN RATS
}

\author{
Tetsuji HIRONAKA, Yumiko OHTAKI, Hitoshi NAKANISHI, \\ Shoji MORIMOTO and Tomoko FUJII \\ Department of Pharmacology. Teikyo University School of Medicine. \\ Kaga 2-11-1. Itabashi-ku. Tokyo 173. Japan
}

Accepted November 5, 1980

\begin{abstract}
The effect of calcium hydroxide on the maximal seizure threshold was studied in 18-day-old rats using the up-and-down method. The maximal seizure was induced by administering an electric shock through the eyes. When calcium hydroxide was given orally once a day $10.04 \mathrm{~m}$ moles $/ \mathrm{kg}$ ) for 10 days from the 8 th to 18 th day after birth, the maximal seizure threshold was raised by $4.8 \mathrm{~mA}$, which corresponded to $16 \%$ of the threshold current in the control. The serum calcium concentration was not significantly altered after the treatment. When calcium chloride was given intraperitoneally, the maximal seizure threshold markedly increased with the increase in serum calcium. It is suggested that the mechanism of the action of calcium hydroxide is different from that induced by increasing the serum calcium.
\end{abstract}

The dissociation constant of calcium hydroxide is so small (1) that most of its molecules should exist in non-ionic form in aqueous solution in the gastrointestinal tract. Since the un-ionized froms of substances penetrate membranes more easily than the ionized forms (2), one could expect a considerable amount of absorption of this substance when it is orally administered. In fact, it has been shown using radioactive tracer techniques that ${ }^{45} \mathrm{calcium}$ in the form of calcium hydroxide is well absorbed when orally administered to the rat (Personal communication).

On the other hand, the calcium ion plays many important roles in physiological functions of the cell. For example, calcium is involved in transmitter release (3), in the regulation of spike generation and membrane conductance following depolarization $(4,5)$. as well as in the modulation of membrane excitability $(6,7)$.

In the present study, the effect of calcium hydroxide on the maximal seizure threshold was investigated in the rat using the "upand-down method" (8).

\section{MATERIALS AND METHODS}

Animals: Rats (Wistar-Imamichi strain) of exactly 18 days of age from the same farm were used for the determination of seizure threshold. Groups of 4 to 10 rats were formed and the ED50 was determined for each group. The groups were formed from the large number of animals necessary for one experiment and randomized for sex, body weight and their mothers fed.

Measurement of seizure threshold: The maximal seizure threshold (MST) was adopted as a criterion because other seizure 
thresholds give ambiguous results in judging the type of the seizures and the specific factors influencing the threshold values (9) The electric shock seizure apparatus was essentially the same as that designed by Woodbury and Davenport (9). The seizure threshold was measured as an a-c current of 0.2 sec duration.

Finding an accurate seizure threshold in one animal requires repeating the shock, which may alter the threshold value of the next shock. The "up-and-down method" was therefore utilized to determine the precise seizure theshold. In this method, usually about 10 rats were used to obtain one mean value, the MST50. When statistical analysis (Table 1) was performed, the entire series of animals was broken up into small groups (cf. 9). The amount of shock current was raised and lowered in steps of $2.5 \mathrm{~mA}$.

The resistance through the brain of the animal between the two eyes was $430 \mathrm{ohm}$ on the average $(n=4)$. This value was incorporated into the series resistance of the circuit together with the polarizing resistance of the corneal electrodes to accurately calculate the current flow in the brain. The corneal electrodes were heavy $(1 \mathrm{~mm}$ diameter) $\mathrm{Ag}-\mathrm{AgCl}$ wire with spiral ends to which a drop of solution could be attatched. A drop of $2 \mathrm{M} \mathrm{NaCl}$ solution containing $2 \%$ procaine was placed in each conjunctival sac to minimize the polarizing resistance of the electrodes and variation between individual shocks. Firm contact of the electrodes with the corneas was confirmed with an ohmmeter in every shock. The pattern of this seizure has been fully described by other workers (9).

Measurement of serum calcium and magnesium concentrations: Immediately after judging the all-or-non type of seizure response, the animal was bled by cutting the jugular vein. The serum was treated with Lantanum-TCA solution and centrifuged at $3000 \times \mathrm{g}$ for $10 \mathrm{~min}$. The supernatant was then used for atomic absorption analysis for determining calcium and magnesium concentrations. In some experiments (Fig. 4). the serum calcium concentration was measured according to the method of Connerty and Briggs (10).

Chemicals: Calcium hydroxide (Tachikawa Penicillin Ltd.) was administered orally. When a high dose of the drug was given, calcium hydroxide suspended in water was used. Each drug was prepared as to give a constant volume $(0.02 \mathrm{ml} / \mathrm{g}$ body weight).

\section{RESULTS}

Effect of orally administered calcium hydroxide on the maximal seizure threshold, and serum calcium and magnesium concentrations: Thirty-two rats consisting of an equal number of male and female animals were fed by 4 mothers and the pups were allotted to the control and the test groups. Calcium hydroxide was orally administered to the test rats with a stomach tube once a day $(0.04 \mathrm{~m} \mathrm{moles} / \mathrm{kg})$ for 10 days from the 8 th to the 18th day after birth, and the same volume of water was given to the control rats. About $20 \mathrm{hr}$ after the final treatment, the MST50 was determined. The maximal seizure threshold of the rats treated with calcium hydroxide was $4.8 \mathrm{~mA}$ higher than that of the control rats, showing a statistically significant difference $(P<0.05$. Student's $t$ test). Both the serum magnesium and calcium concentrations were slightly decreased by the treatment (Table 1). The former attained a statistically significant difference between the two groups $(P<0.01)$, but the latter did not.

Effects of acutely administered calcium hydroxide and sodium carbonate on the maximal seizure threshold: The maximal seizure threshold was determined in 18-dayold rats which had orally been given a constant volume of calcium hydroxide solution $30 \mathrm{~min}$ before the shock. The 
Table 1. Maximal seizure threshold (mA), and serum calcium and magnesium concentrations ( $\mathrm{mM}$ ) of the rats treated with calcium hydroxide or water

\begin{tabular}{|c|c|c|c|c|c|c|}
\hline \multirow[b]{2}{*}{ Group } & \multicolumn{3}{|c|}{$\mathrm{Ca}(\mathrm{OH})_{2}$} & \multicolumn{3}{|c|}{ Water } \\
\hline & $\begin{array}{c}\text { MST5O } \\
\text { (mA) }\end{array}$ & $\begin{array}{c}\mathrm{Ca} \\
(\mathrm{mM})\end{array}$ & $\begin{array}{c}M g \\
(m M)\end{array}$ & $\begin{array}{c}\text { MST50 } \\
\text { (mA) }\end{array}$ & $\begin{array}{l}\mathrm{Ca} \\
(\mathrm{mM})\end{array}$ & $\begin{array}{l}M g \\
(m M)\end{array}$ \\
\hline 1 & 33.8 & 2.50 & 1.23 & 28.8 & 2.54 & 1.27 \\
\hline 11 & 35.0 & 2.58 & 1.21 & 30.0 & 2.57 & 1.31 \\
\hline$\| 11$ & 31.9 & 2.58 & 1.20 & 27.5 & 2.68 & 1.31 \\
\hline IV & 33.8 & 2.41 & 1.22 & 28.8 & 2.65 & 1.24 \\
\hline Meant S.E.M. & $33.6 \pm 0.64$ & $2.52 \pm 0.039$ & $1.22 \pm 0.006$ & $28.8 \pm 0.51$ & $2.61 \pm 0.34$ & $1.28 \div 0.017$ \\
\hline
\end{tabular}

The values were determined in rats treated for 10 days. There was no obvious difference in the body weight between the two groups when the treatments were started, $15.5 \pm 0.26$ (moñS.E.) and $14.8 \pm 0.34 \mathrm{~g}$ for the control and the test, and when the MST50 was determined, $35.2 \pm 1.48$ ard $34.8 \pm 1.04 \mathrm{~g}$, respectively.

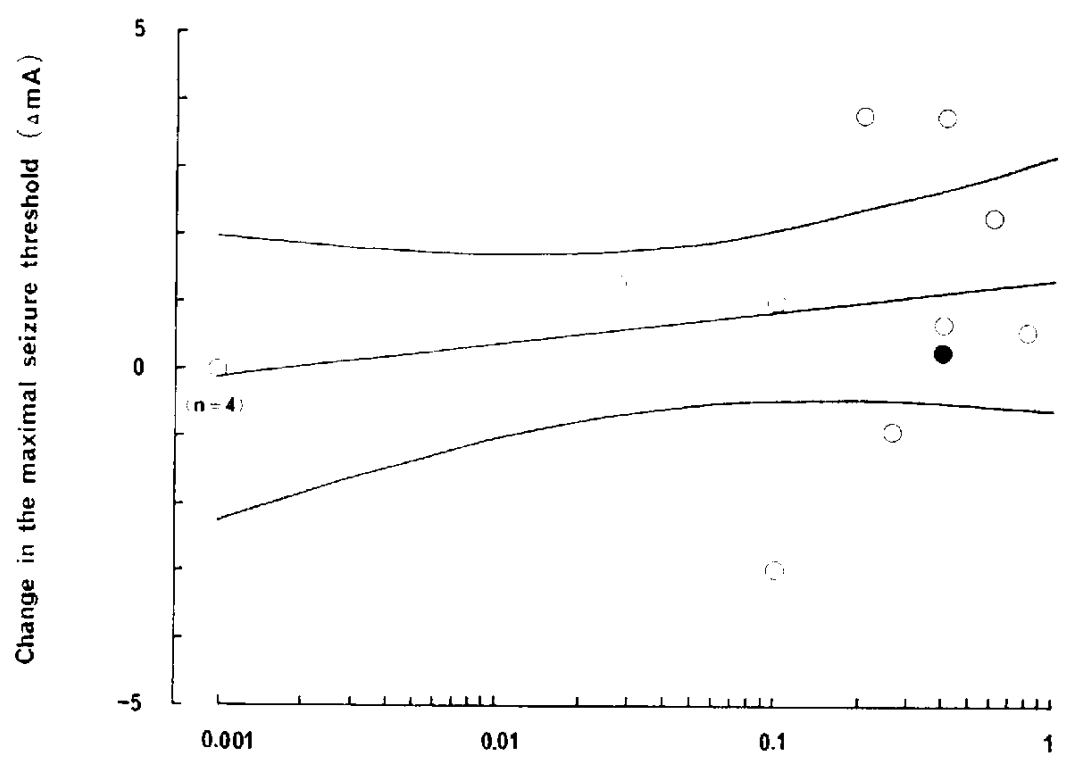

Dose (m moles $/ \mathrm{kg}$, p.o. $)$

Fig. 1. Effects of arally administered calcium hydroxide and sodium carbonate on the maximal seizure tireshold. Ordinate: difference in the maximal seizure threshold in mA between the control and the test rats. (The differcnce was used because the data were from different experiments). Abscissa: logarithm of the orally administered drug dose. Open circles, calcium hydroxide. Filled circle, sodium carbonate. The straight line, a linear regression with its confidenco limits (Student's t-test. P<0.05).

difference in the threshold current between the control and the test rats was plotted against the log of the drug dose (Fig. 1). The results showed that the threshold tended to increase with the dose. Higher doses could not be given because of the pylorus spasm. so that it was not clear whether or not the corresponding effective dose in the acute experiment was adequate.

When a large amount of sodium carbonate 
$(0.4 \mathrm{~m}$ moles $/ \mathrm{kg})$ is added to the $\mathrm{HCl}$ in the stomach, the two chemicals constitute a buffer system ensuring a high $\mathrm{pH}$ of 10-11 (11). This high $\mathrm{pH}$ did not produce a significant change in the seizure threshold (filled circle in Fig. 1).

Effects of acutely administered calcium hydroxide on the serum calcium and magnesium concentrations: The same volume of calcium hydroxide solution containing various concentrations was orally administered as in Fig. 1, and the serum calcium and magnesium concentrations were determined 30 min afterwards (Fig. 2). Both the serum calcium (open circles) and magnesium (filled circles) concentrations decreased slightly in a dose-dependent manner.

Relationship between the maximal seizure threshold and the serum magnesium concentration: Acute hypermagnesemia was induced by giving magnesium chloride solution intraperitoneally. The MST50 determined $10 \mathrm{~min}$ after the injection and plotted against the serum magnesium concentration on a semilogarithmic scale is shown in Fig. 3. The MST50 was not significantly altered with the serum magnesium in the range of the concentration shown in Table 1 (between the two arrows in Fig. 3).

Relationship between the maximal seizure threshold and the serum calcium concentration: Acute hypercalcemia was induced by intraperitoneal injection of calcium chloride solution. The maximal seizure thresholds determined 10 min after the application were plotted against a logarithm of the serum calcium concentrations in Fig. 4. As the serum calcium was raised, the threshold current increased linearly. In contrast, when the calcium hydroxide was orally adminis-

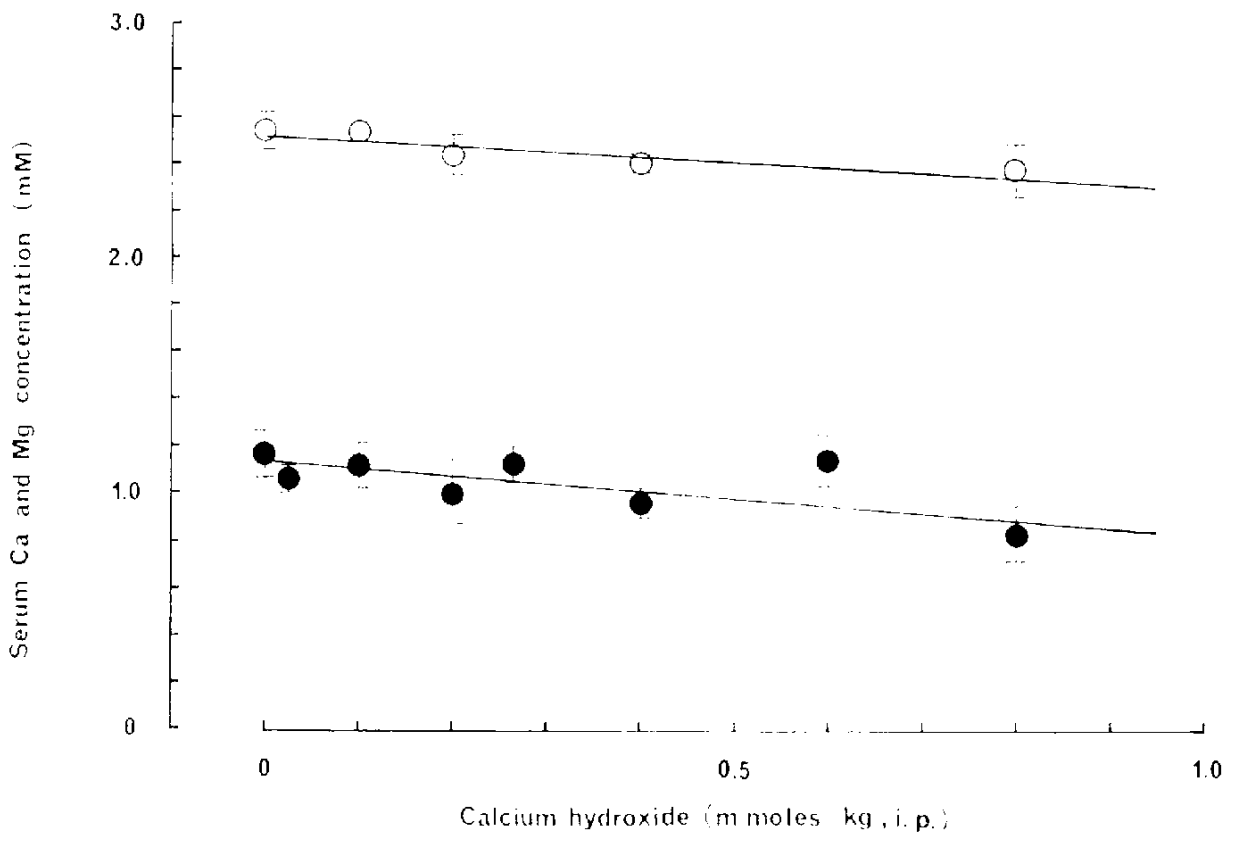

Fig. 2. Effects of oraly administera calcum tycroxide on the serum calcium and magnesium concentrations. Ordinate: serum calcium (open circles) and magnesium (closed circles) concentrations in $\mathrm{mM}$. Abscissa: calcium hydroxide in m mole $/ \mathrm{kg}$ body woight. The drug was applied 30 min betore measuremert. The corrolation coefficiont for the regression line was -0.87 witl: P .0 .05 for the caicium and -0.65 with $P \cdot 0.05$ for the magnesium. The vertical bars show S.D. 


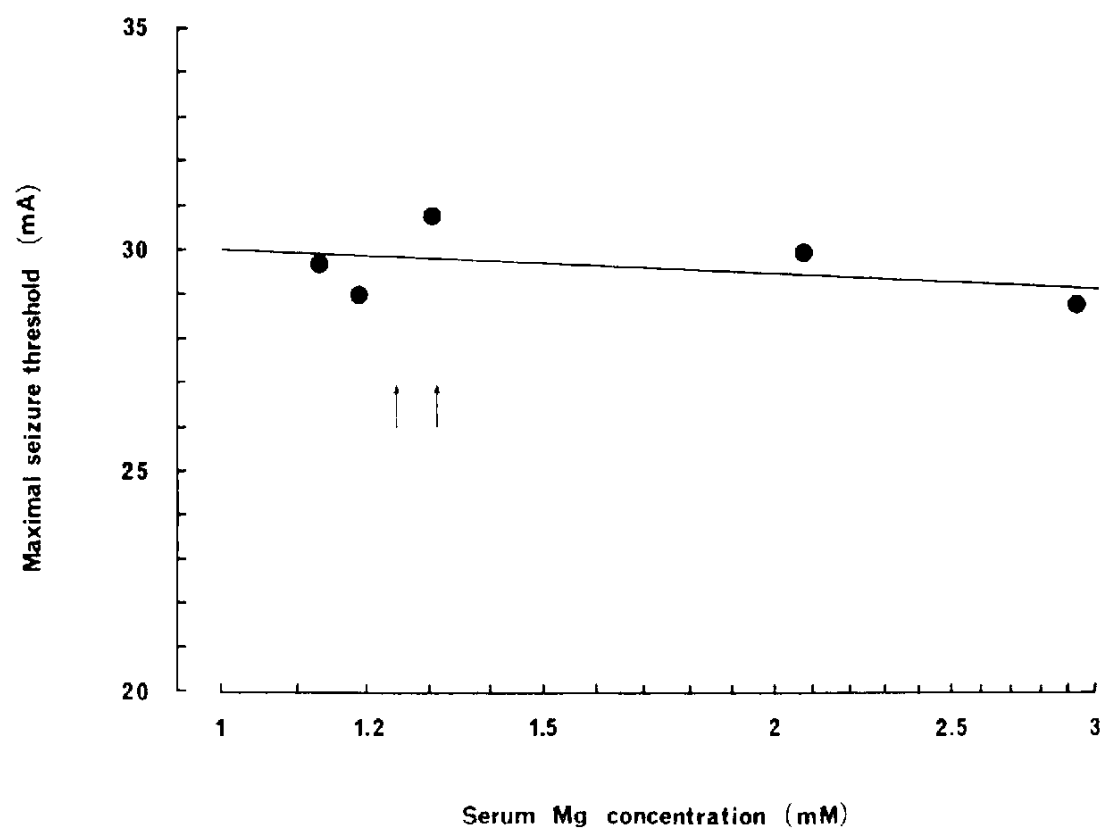

Fig. 3. Relationship between the maximal seizure threshold and the sorum magnesium concentration. Ordinate: Maximal seizure threshold in mA. Abscissa: logarithm of serum magnesium concontration in $\mathrm{mM}$. The change in the serum magnesium concentratior. between the two arrows corresponds to that induced by the chronic treatment with calcium hydroxide showin in Tablo 1.

tered 30 min before the shock, the threshold elevation was not associated with any increase in the serum calcium (filled circles in Fig. 4). The serum calcium rather decreased in the latter case in proportion to the dose (Fig. 2). The increase in the threshold for the groups treated with calcium hydroxide (marks 1 and 2 in Fig. 4) may be a result of the treatment, because the threshold for the control rats attained very close values in each case (Figs. 3-5).

Effects of intraperitoneally applied calcium hydroxide and calcium carbonate on the maximal seizure threshold: Higher doses of calcium hydroxide suspended in water and calcium carbonate were injected into the intraperitoneal cavity and the seizure threshold was determined $10 \mathrm{~min}$ after the application (Fig. 5).

Neither calcium hydroxide nor calcium carbonate gave a statistically significant change for the maximal seizure threshold in a dose-dependent manner. The serum calcium concentration did not increase even when calcium hydroxide was administered intraperitoneally (filled circles in Fig. 6), but this concentration greatly increased when calcium chloride was administered (open circles). The concentration of serum magnesium was not significantly affected by increase in the levels of serum calcium.

\section{DISCUSSION}

In the present study. two points are to be emphasized: first, the "up-and-down method" was utilized to determine a precise maximal seizure threshold, thus, the results could be analyzed more quantitatively; second, newborn rats were used for the threshold determination. In the rat brain, only an elementary stage of differentiation has been reached at birth, and the subsequent 


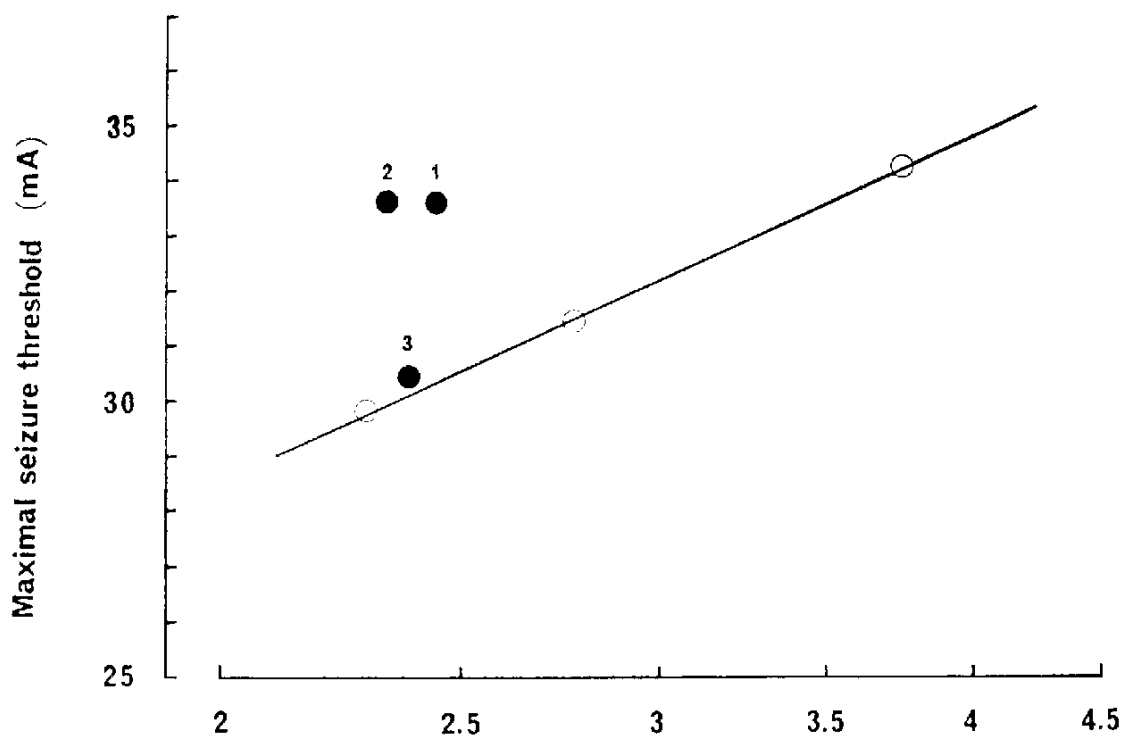

\section{Serum $\mathrm{Ca}$ concentration $(\mathrm{mM})$}

Fig. 4. Relationship Detween the maximal seizure threshold and the serum calcium concentration. Ordinate: maximal seizure threshold in mA. Abscissa: log concontration of serum calcium in miv. Open circles, calcium chloride (i.p.). Filled circles, calcium lydroxide (p.o.) $1,0.2: 2,0.4: 3,0.8 \mathrm{~m}$ moles $/ \mathrm{kg}$ body weight, respectively.
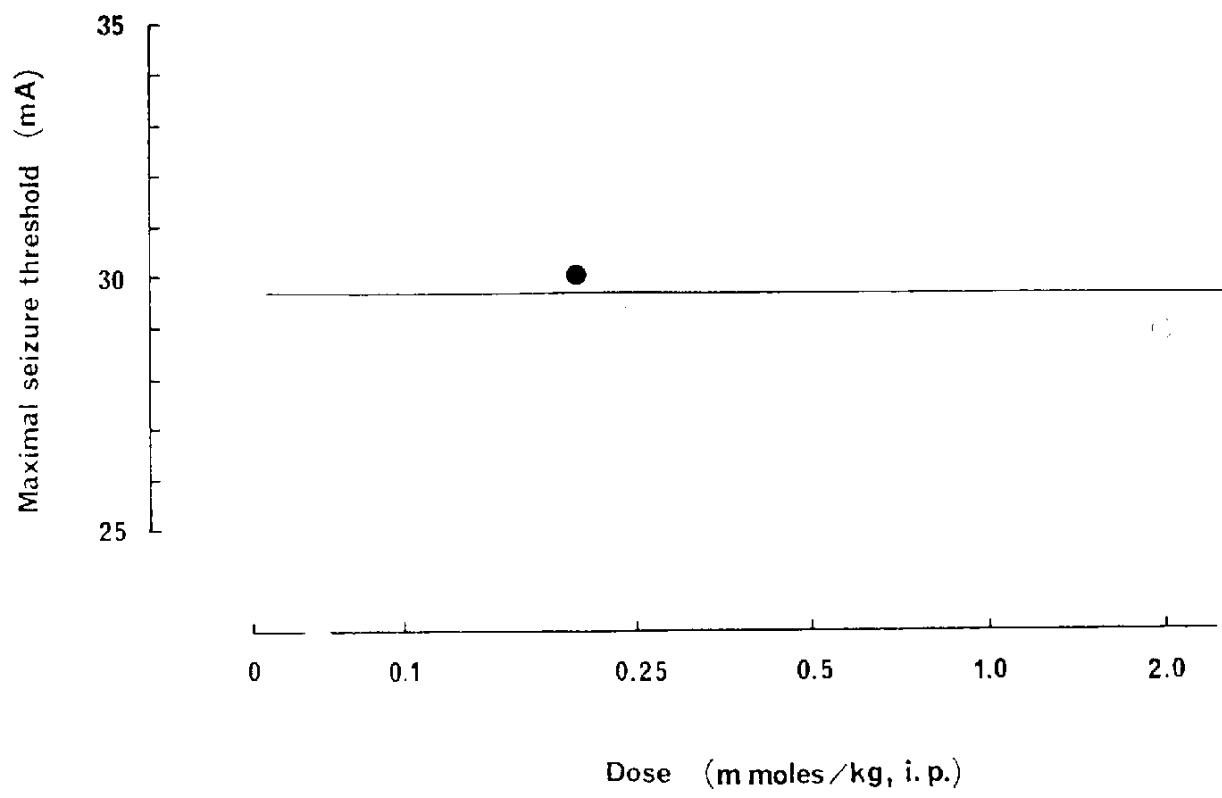

Fig. 5. Effects of intraperitoneally aoplied calcium hydroxide and calcium carbonate on tho maxmal stikum tresiold. The relation is illustrated on a semilogaritamic scalo. Open circles, cacium rydroxide. Fillod circle calcium carbonate. Correlacion coefficient. -0.003 . 


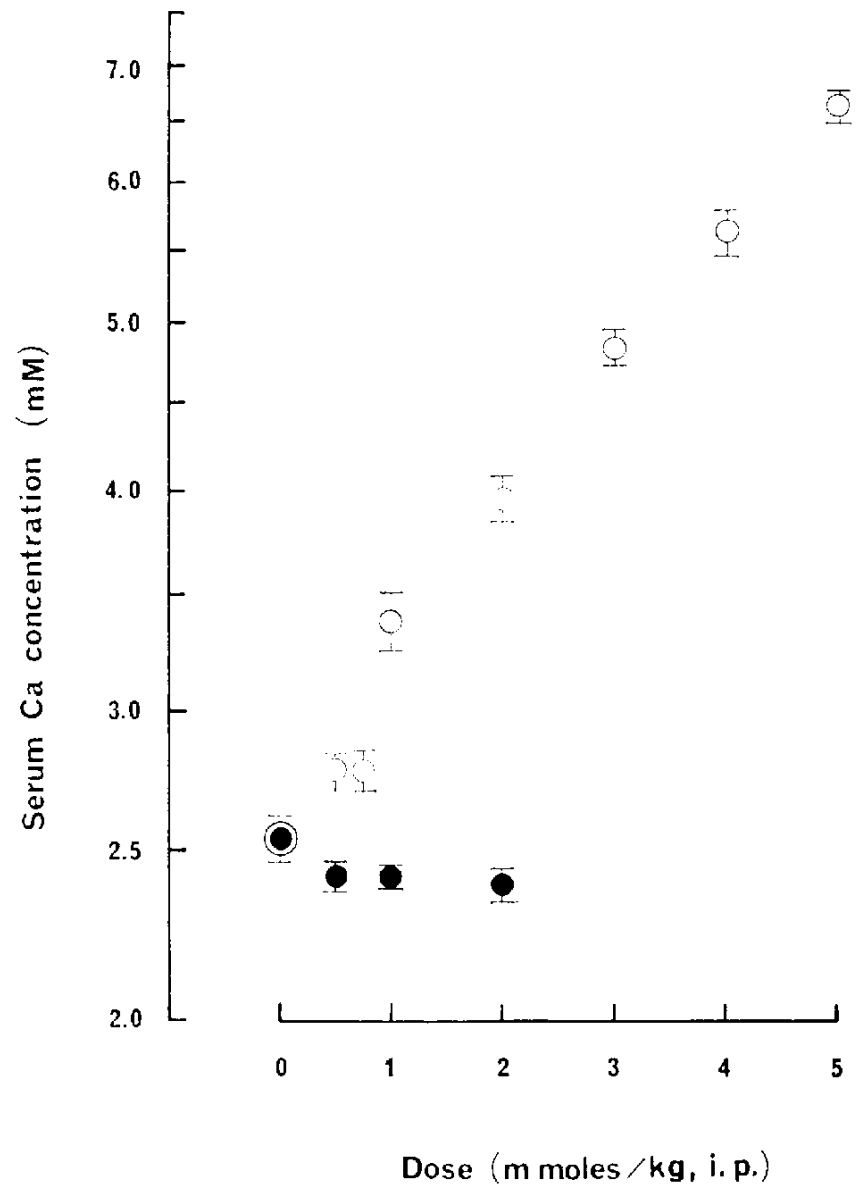

Fig. 6. Changes in the serum calcium concentration induced by intraperitoneal administration of calcium chloride (open circles) and calcium hydroxide (filled circles). Circles and vertical bars are mean and S.E. The values were determined $10 \mathrm{~min}$ after the injection.

development continues for more than three weeks (12). It has also been demonstrated that newborn rats attain a postnatal development of the blood-brain barrier in electrolyte metabolism $(13,14)$ and for the neurotoxin action $(15,16)$.

The rats which had been given calcium hydroxide for 10 days attained a seizure threshold $4.8 \mathrm{~mA}$ higher than that of the control rats (Table 1). This amount of current corresponded to $16 \%$ of the seizure threshold of the control rats, suggesting a physiological significance of the change. After the administration of calcium hydroxide, however, not only the serum magnesium but also the calcium concentration was reduced, in a dose-dependent manner (Figs. 2, 6). Since a minute amount of divalent cations exerts a substantial effect on the excitability of the nerve membrane in terms of the surface potential $(6,7,17-19)$, the effects of serum calcium and magnesium on the MST50 were quantitatively determined in Figs. 3 and 4 . The results excluded the possibility that the slight decrease in the divalent cations associated with the treatment by calcium hydroxide may be the cause of the elevation of the MST5O observed in 


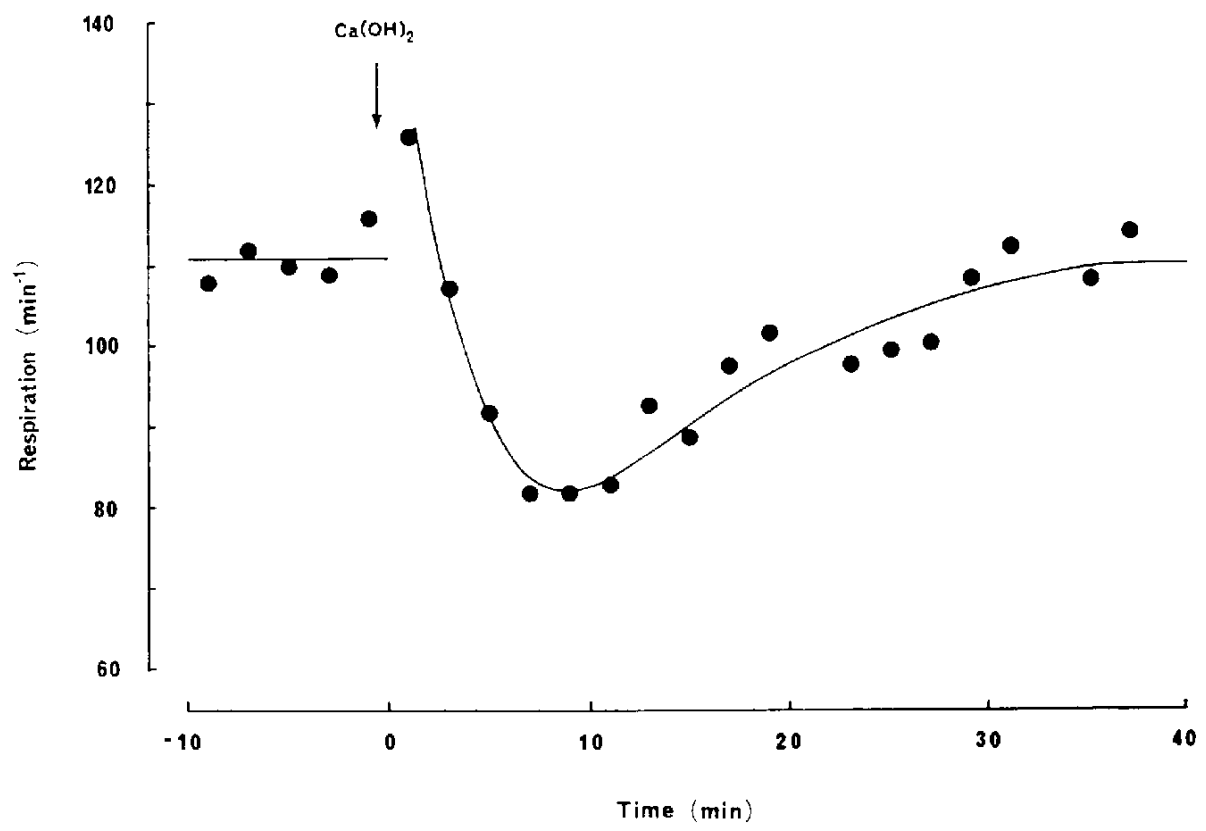

Fig. 7. Respiratory suppression produced by calcium hydroxide. The drug was intraperitoneally applied in a dose of $0.4 \mathrm{~m}$ moles $/ \mathrm{kg}$ at the arrow. A rat was immobilized in a glass cylinder in order to count the number of the respirations/min.

Table 1. Namely, an expected elevation of the seizure threshold due to the decrease in the serum magnesium in Fig. 3 was too little to explain the threshold elevation (4.8 $\mathrm{mA}$ ), and the expected effect brought about by the decrease in the serum calcium was conversely a decrease in the seizure threshold (Fig. 4). It was clearly shown that the mechanism of the action of calcium hydroxide was different from that of calcium chloride (Figs. 4, 6).

Although the slight decrease in the serum calcium after calcium hydroxide shown in Figs. 2 and 6 appears to contradict a previous study (Personal communication), it is likely that calcium hydroxide has been redistributed after absorption, for the behaviour of $\mathrm{Ca}^{++}$in the blood is known to be closely related to the change of $\mathrm{pH}(20)$. Calcium hydroxide itself is highly alkaline, so that the acute treatment by the drug may be accompanied by alkalosis, although the following hypocapnea (Fig. 7) might counteract this effect to some extent. If hydrogen ions have an effect similar to divalent ion on the surface potential shift (19), the effect of calcium hydroxide on the threshold increase observed in the chronic treatment (Table 1) might be covered up by the $\mathrm{pH}$ effect in the acute treatments (Figs. 1, 5). Calcium carbonate, however. did not exhibit any significant effect on the seizure threshold (filled circle in Fig. 5). Because of technical difficulties it was not determined whether the $\mathrm{pH}$ in the blood was altered when the threshold current was measured.

A high $\mathrm{pH}$ associated with the application of calcium hydroxide in the gastrointestinal tract may not be the cause for the change in the MST50 as illustrated in Fig. 1 (filled circle), at least in the acute experiments.

From these considerations, it seems that although calcium appears to be related somehow to the elevation of the maximal seizure threshold (Table 1), the effect is not due to a direct action of calcium or its related 
compounds, but from an effect on CNS function induced indirectly and chronically by calcium hydroxide, a synaptic event. Details of the mechanism are the subject of ongoing studies.

\section{REFERENCES}

1) Handbook of Chemistry and Physics. 47 th edn. Edited by Weast, R. C., p. D-85. The Chemical Rubber Co. Ohio, U.S.A. (1966-1967)

2) Davson, H.: A Toxtbook of General Physiology. Vol. 1. p. 395-507, J. \& A. Churchiil, London (1970)

3) Katz, B. and Miledi, R.: Tetrodotoxin-resistant electric activity in presynaptic terminals. J. Physicl. 203, 459-487 (1969)

4) Meech, R.W.: Intracellular calcium injection causes increased putassium conductance in Aplysia nerve cells. Comp. Biochom. Physiol. A. 42, 493-499 (1972)

5) Barrett, E.F. and Barrett, J.N.: Separation of two voltage-sensitive potassium currents, and demonstration of a tctrodotoxin-resistant calcium current in frog motoneurones. $J$. Physiol. 255, 737-774 (1976)

6) Frankenhaeuser, B. and Hodgkin, A.L.: The action of calcium on the electrical propertics of squid axons. J. Physiol. 137, 218-244 (1957)

7) Hironaka, T. and Morimoto, S.: Computer analyses of the excitable membrane. Computers and Biomed. Res. 13, 36-51 (1980)

8) Brownlee, K.A., Hodges, J.L., Jr. and Rosenblatt, M.: The up-and-down method with small samples. J. Amer. Statist. Assoc. 48, 262-277 (1953)

9) Woodbury, L.A. and Davenport, V.D.: Dcsign and use of a now electroshock seizure apparatus, and analysis of factors altering seizure throshold and pattern. Archs int. Pharmacodyn Thér. 92, 97-107 (1952)

10) Connerty, H.V. and Briggs, A.R.: Determination of serum calcium by means of orthocresophthalein complexone. Am. J. Clin. Path. 45, 290-296 (1966)

11) Kolthoff, I.M.: Der Gebrauch von Farbindikatoren. 2 Aufl., S. 122, Julius Springer, Berlin (1923)

12) Eayrs, J.J. and Goodhead, B.: Postnatal devclopment of the cerebral cortex in the rat. J. Anat. 93, 385-402 (1959)

13) Chaikoff, I.L.: The application of labeling agents to the study of phospholipid metabolism. Physiol. Rev. 22, 291-317 (1942)

14) Katzman, R. and Leiderman, P.H.: Brain potassium exchange in normal adult and immature rats. Am. J. Physiol. 173, 263-270 (1953)

15) Sacks, C.: Development of the blood-brain barrier for 6 -hydroxydopamine. J. Neurochem. 20,1753-1760 (1973)

16) Sacks, D. and Jonsson, G.: Changes in central noradrenaline neurons after systemic 6 -hydroxydopamine administration. J. Neurochem. 21. $1517-1524$ (1973)

17) Gilbert, D.L. and Ehrenstein, G.: Effect of divalent cations on potassium conductance of squid axons: determination of surface charge. Biophys. J. 9, 447-463 (1969)

18) McLaughlin, S.G.A., Szabo, G. and Eisenman, G.: Divalent ions and the surface potential of charged phospholipid membranes. J. gen. Physiol. 58, 667-687 (1971)

19) Hille, B.: Negative surface charge near sodium channels of nerve: divalent ions, monovalent ions, and pH. Phil. Trans. R. Soc. B 270, 301$318(1975)$

20) Greger, R., Oberleithner, H., Land, F. and Sporer, $\mathrm{H} .: \mathrm{HCO}_{3}{ }^{-}$and $\mathrm{pH}$-dependent concentration changes of ionized calcium: an in vivo study utilizing continuous measurement. Fourth Intn. Workshop on Phosphate and other Minorals. Mineral and Electrolyte Metab. 2, $230(1979)$ 